\title{
Course of adolescent headache: 4-year annual face-to-face follow-up study
}

\author{
Necdet Karlı • Aylin Bican · Mehmet Zarifoğlu
}

Received: 28 December 2009/Accepted: 18 May 2010/Published online: 5 June 2010

(C) Springer-Verlag 2010

\begin{abstract}
The objective of this study is to investigate the course of the diagnosis and characteristics of headache in 12- to 17-year-old adolescents during a follow-up period of 4 years. Headache prevalence and characteristics, and even the type of headache show important changes during adolescence. The course of adolescent headache might reveal important insight into the pathophysiology of headache. Subjects who received a single headache diagnosis were invited to participate in a follow-up study consisting of annual face-to-face evaluation of the subjects for 4 years. Subjects who had only one type of headache and who agreed to participate were included in the study. Each subject had four annual semi-structured interviews with a neurology resident. The International Classification of Headache Disorders second edition was used for case definitions. A total of 87 subjects completed the study: 64 girls $(73.56 \%)$ and 23 boys $(26.44 \%)(p=0.016)$. The headache type included migraine in 50 adolescents $(57.47 \%)$, tension type headache in $24(27.59 \%)$, secondary headache in $5(5.7 \%)$, and non-classifiable headache in 8 (9.2\%). Headache has not remitted in any of the subjects. Headache diagnosis has changed in eighteen (20.69\%) subjects at least once during the follow-up period. There was transformation of headache type in 4 of 50 with migraine (8\%), 10 of 24 with tension-type headache (TTH) $(41.7 \%)$, and 4 of 13 with other headaches $(30.8 \%)$. In conclusion, transition of headache types from one type to another (more than once in some adolescents) and variability of diagnosis throughout the years strongly support the continuum theory of headaches.
\end{abstract}

N. Karlı $(\bowtie) \cdot$ A. Bican · M. Zarifoğlu

Department of Neurology, School of Medicine, University of Uludag, 16059 Bursa, Turkey

e-mail:nkarli@uludag.edu.tr; nkarli@yahoo.com
Keywords Adolescent $\cdot$ Headache $\cdot$ Migraine . Tension-type headache $\cdot$ Course $\cdot$ Transformation

\section{Introduction}

Headache is a common disorder in adolescents, with reported prevalence ranging from 52.2 to $82 \%$. The variation in estimates reflects differences in study population, as well as methodological differences such as type of prevalence estimate, case definition criteria, and assessment methods (telephone interview, mail questionnaires, and face-to-face interview) [1-5]. In 12- to 17-year-old adolescents in Bursa, Turkey, the 1-year prevalence of recurrent headache was $52.2 \%$, the estimated 1-year prevalence of migraine was reported to be $14.5 \%$, and the oneyear prevalence of episodic tension type headache (ETTH) was reported to be $30.2 \%$ [1].

Particularly with regard to migraine headaches, adolescence seems to be a bridge period between childhood and adulthood headache; it has been observed that characteristics of adolescent headaches might differ from those of headaches in adulthood [6-9]. The International Headache Society (IHS) has defined characteristics for migraine in persons younger than 18 years of age in the second edition of International Classification of Headache Disorders (ICHD-2). Duration, lateralization, and accompanying features are some of these differences [10].

Adolescence is a complex period of life with hormonal, physiological, and psychological changes. These changes may affect many aspects of headache and may result in: (1) differences in type and prevalence of headache compared with childhood and adulthood; (2) variability in prevalence between sexes; (3) differences in headache characteristics between adolescence and adulthood [1-5, 11, 12]. Migraine 
prevalence is similar before puberty in both sexes; however, after puberty, migraine becomes more prevalent in girls. Female sex hormones may be responsible for this shift [2, 13-15].

Nachit-Ouinekh et al. [16] reported that headache symptoms and diagnosis showed variability in adults during a prospective 1-year study. Prospective follow-up studies have also shown that migraines remit in 17-38.2\% of children and adolescents [17-23], and that adolescent headaches may transform from one type to another (from migraine to ETTH and vice-versa) [17-19, 21, 23-26]. The changes of adolescence may have an important role in the pathogenesis and variability of headache during this stage of life.

In this study, we aimed to investigate changes and transformation of headache types and clinical features of headache for 4 years during adolescence.

\section{Methods}

Volunteers from a previous school-based study were recruited for this study. All adolescent subjects diagnosed with recurrent headache of a single type in our previous school-based prevalence study were contacted by telephone and were asked to participate in a follow-up study comprising face-to-face evaluation of the subjects on an yearly basis for four consecutive years [1]. Only subjects with a single headache type were contacted, in order to observe the transformation of headache types, and clinical characteristics. Subjects who agreed to participate and whose parents signed the consent forms were included in the study. All subjects were evaluated annually for four consecutive years for diagnosis, clinical characteristics, accompanying symptoms, and trigger factors according to the ICHD-2 criteria (appropriate criteria were used for those under 18 and those 18 years and older). Headaches that could not be classified were grouped as "other" headaches. Subjects free of headache attack during the last 12 months were classified as headache free.

Each subject had a semi-structured face-to-face interview with a second-year (at the beginning of the study) neurology resident (A.B.) (having completed 6-month headache outpatient clinic rotation at the beginning of the study) every year. One of the headache experts (N.K. or M.Z.) evaluated the subjects whenever the resident was unsure of diagnosis or related aspects. Preventive or acute medical treatment, (e.g., triptan, nonsteroidal anti-inflammatory agents) was planned to prescribe whenever needed and in agreement with the subject and the family. None of the subjects who needed preventive treatment agreed to take preventive treatment. All preferred acute attack treatment. The study protocol was reviewed and approved by the institutional ethics committee.
Data were analyzed by SPSS for Windows version 13.0 (Chicago, IL). For comparisons, Mann-Whitney $U$ test was used to evaluate the difference of continuous variables and Pearson chi-square test for categorical variables between patient groups. McNemar test was used to detect the significant difference between first and second classification of all other categorical variables; $p<0.05$ was deemed as statistically significant.

\section{Results}

Five hundred and seventy-two $(56.35 \%)$ out of 1,015 eligible subjects could be contacted. One hundred and thirty-nine subjects volunteered for the study. Of those, 87 $(62.59 \%)$ completed the study. Subjects who did not complete the study either were lost to follow-up, moved to other cities, started university in another city, gone for military service, did not wish to continue to participate, or cited an intense schedule of classes as the reason for discontinuation. All subjects who left the study did so in the first and second years, mostly after the first follow-up visit. All sociodemographic and socioeconomic variables of the subjects and families, and headache characteristics of the subjects have been compared between the dropouts and the study group. Mean age was significantly younger $(13.05 \pm 0.82)$ in the dropout group $(p<0.05)$ and the number of girls were significantly higher in the study group $(p=0.016)$. All other parameters of the subjects and families did not show any significant difference between the two groups. Only the subjects who completed the study ( $n=87$ ) were analyzed to evaluate the mid-term course of the headaches.

Mean age was $14.28 \pm 1.78$ years for the study group. Among the 87 members of the study group, 64 were girls $(73.56 \%)$ and 23 were boys $(26.44 \%)$. Mean age of girls was $13.56 \pm 0.79$, and of the boys was $14.73 \pm 1.02$ $(p=0.032)$. There were significantly more migraine sufferers in the study group than in the contacted group $(p<0.001)$. All of the girls were post-menarchal, and all of them were accepted as adolescents. The most common diagnosis was migraine (all migraine without aura) in 50 $(57.47 \%)$ adolescents, followed by tension-type headache (TTH, all episodic tension type) in 24 (27.59\%), and unclassified headache in 13 (14.94\%). All subjects had only one headache diagnosis. Diagnoses and course of headache types during 4-year follow-up period are shown in Table 1. The headache diagnosis of 18 subjects $(20.69 \%)$ changed at least once during the follow-up period. There was transformation of 4 of 50 headaches in those who initially reported migraine (8\%); 10 of 24 with TTH (41.7\%); and 4 of 13 other headaches $(30.77 \%)$. The highest transformation rate was found in migraine and probable migraine 
Table 1 Headache types and transformation of headaches throughout the study $(n=87)$

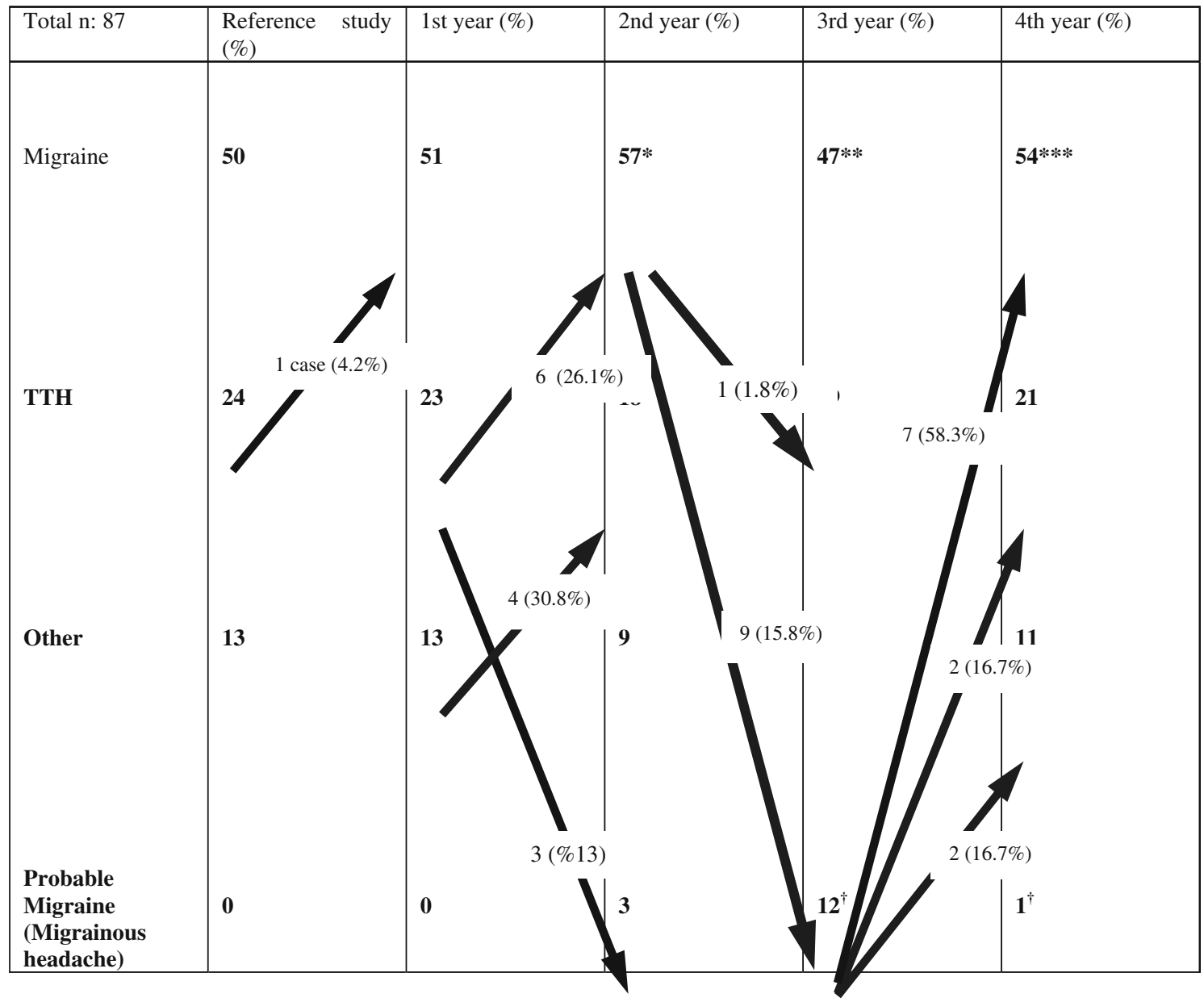

TTH tension type headache

$* p=0.002 ; * * p=0.001 ; * * * p=0.002 ;{ }^{\dagger} p<0.001$. All others not significant. All compared to previous year

(PM) groups. The difference between the first and the final diagnoses was not significant in any headache type. However, migraine diagnosis showed significant variability from year to year throughout the study. The highest rate of transformation between headache types occurred between the first and second years $(n=13)$.

In order to investigate the effects of age, subjects were further divided in to two groups; the 12- to 14-year-old group, and the 15- to 17-year-old group, according to their ages at the time of the previous study [1]. Yearly headache diagnosis data are shown by age group in Tables 2 and 3 . There were 44 subjects (30 girls, 14 boys) in the 12 - to 14-year-old group and 43 subjects ( 34 girls, 9 boys) in the 15- to 17-year-old group. A total of 35 transformations of headache type occurred in 18 adolescents throughout the study. Fifteen of $18(83.33 \%)$ subjects whose headache transformed into another headache type were in the younger group. Thirty of 35 headache transformations $(85.71 \%)$ occurred in the same group, as well. The evolution of headache for each subject is shown in Table 4. There was no significant difference in headache transformation between the sexes in the 12- to 14-year-old group (10 girls, 5 boys). Statistical analysis could not be performed in the 14- to 17-year-old group due to small numbers, but all headache transformations occurred in boys. The average headache transformation per subject was approximately two, varying from one to three. Four of 50 adolescents with migraine $(8 \%)$, and 10 of 24 with TTH $(41.7 \%)$ had transformation to other headache types.

Nausea, increased severity with daily routine activity, phonophobia, stress, hunger, and sleeplessness showed significant increase in migraine patients $(p<0.05)$. Nausea, phonophobia, stress, and sleeplessness showed significant variability during the study period in the 12- to 14-year-old migraine group $(p<0.05)$ (Table 5). None of the stable TTH characteristics, associated symptoms, or trigger factors showed significant difference during the study. 
Table 2 Course of headache types and transition between each headache type in 12- to 14-year-old adolescents ( $n=44$ subjects)

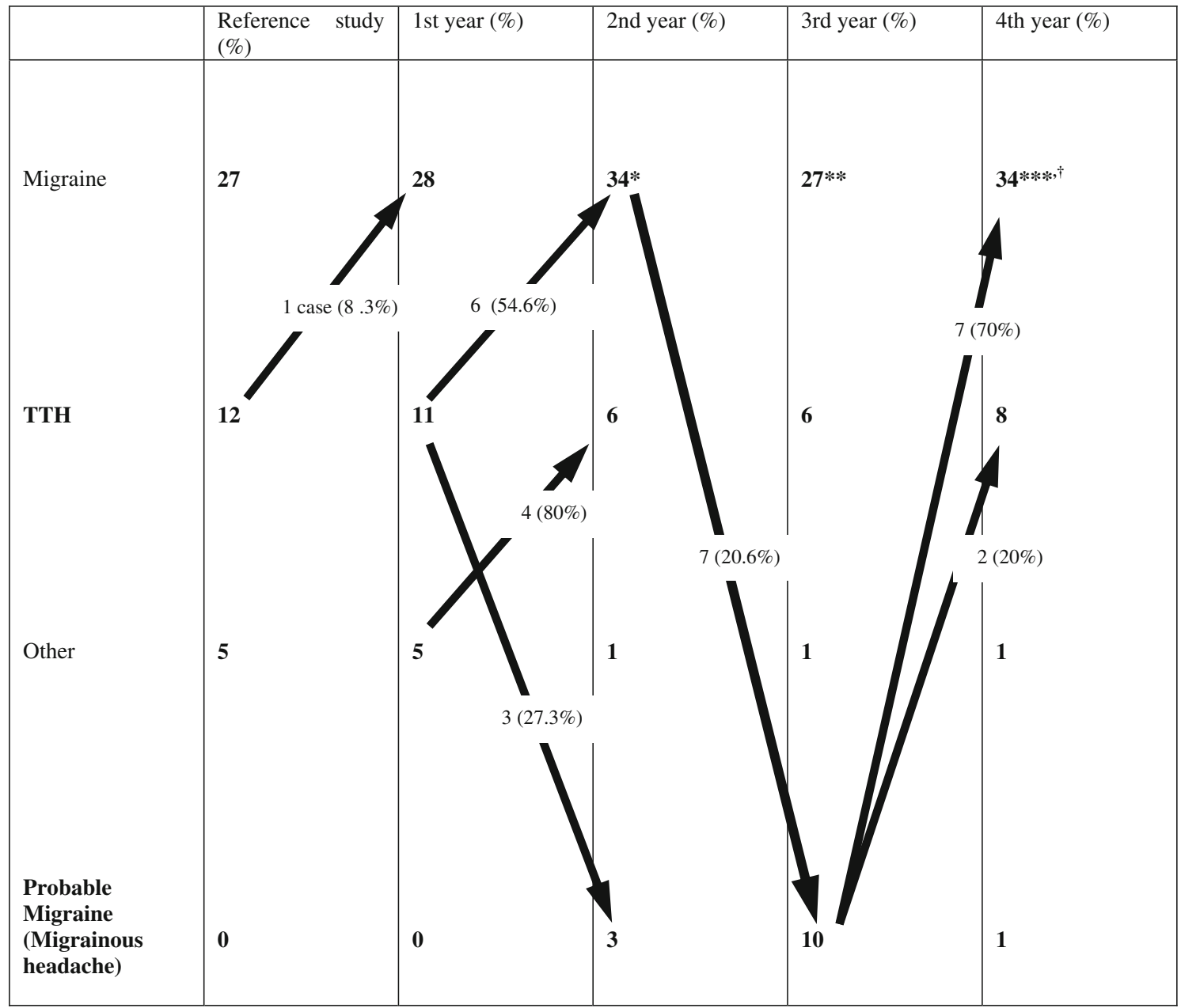

TTH tension type headache

$* p=0.01$ compared to first year; $* * p=0.02$ compared to second year; $* * * p=0.02$ compared to third year; ${ }^{\dagger} p=0.02$ compared to the reference study. All others not significant

\section{Discussion}

This 4-year study with annual face-to-face interviews provides valuable data on the evolution of the unstable clinical disorder of adolescent headache. More than $20 \%$ of the subjects had a headache type that transformed into another headache type during the follow-up period. Of particular interest, each subject's headache type changed approximately two times.

In our study, none of the subjects experienced remittance of headaches. This result is in contrast with findings of other studies [13, 17-21, 23-28]. It has been reported that migraine remits in $10.5-46 \%$ of migraine sufferers $[13,17,18,20,21,23-28]$ and TTH has been reported to remit in $23-44.4 \%$ of TTH sufferers after different periods of follow-up [17, 18, 21, 25, 26, 28]. High variability between studies reflects different study populations and study methods as well as different follow-up periods (1-40 years).

It is remarkable that none of the headache sufferers experienced remission of headaches in our study. Selection bias might have caused this discrepancy. According to our study methodology, only adolescents diagnosed with a single headache type were invited to participate. It is possible that subjects suffering from more severe headache, and those who were concerned about their headaches might have agreed to participate, contributing to the lack of remission in our patient population. The observation that the rate of migraine is greater in the study group than in the contacted group supports our hypothesis. In addition, annual face-to-face interviews might have increased the awareness of subjects about headache, and might have 
Table 3 Course of headache types and transition between each headache type in 15- to 17-year-old adolescents ( $n=43$ subjects)

\begin{tabular}{|c|c|c|c|c|c|}
\hline & $\begin{array}{l}\text { Reference study } \\
(\%)\end{array}$ & 1st year $(\%)$ & 2nd year $(\%)$ & 3rd year $(\%)$ & 4th year $(\%)$ \\
\hline Migraine & 23 & 23 & 23 & 20 & 20 \\
\hline TTH & 12 & 12 & 12 & 13 & 13 \\
\hline Other & 8 & 8 & 8 & 8 & 10 \\
\hline $\begin{array}{l}\text { Probable } \\
\text { Migraine } \\
\text { (Migrainous } \\
\text { headache) }\end{array}$ & 0 & 0 & 0 & 2 & 0 \\
\hline
\end{tabular}

TTH tension type headache

drawn the attention of subjects to their headaches. This might have increased the recollection of the headache attacks during the previous year, and resulted in the lack of headache-free subjects at the end of the study. Our finding about the remission rate opens a discussion point on the epidemiological data that a maximum of only $5 \%$ of this study group could have been classified as 'headache free' given the definition of headache used in this study [20].

Apart from the studies by Wang et al. [19] and Kienbacher et al. [28], most studies involved two evaluations, at the beginning and end of the follow-up period, and the shortest time period between the two evaluations was 3 years $[13,17,18,20,21,23,24,26]$. Although Gassmann et al. [25] reported a 1-year follow-up period, their study population was younger, and they used mail questionnaires answered by parents. It is difficult for children and teenagers to remember rare or short-lasting headaches that occurred 3-8 years previously. It is thus possible that subjects were not able to recall some headache attacks, resulting in increased numbers of falsepositive headache-free subjects. The term "headache free" was defined in a number of studies [17, 23, 25, 27, 28]. These studies required different time periods and headache frequencies to classify the subjects as headache free. In our study, subjects who did not experience a headache attack in the previous 12 months were classified as headache free. This might be another factor in our low remission rate.

Face-to-face interviews are accepted as the gold standard in headache studies. Most other studies involved headache questionnaires and telephone interviews, which might have been inadequate for subjects to remember headaches or ask explanatory questions [13, 19, 25, 26]. Metsahonkala et al. [27] reported a lower remission rate $(5 \%)$ of migraine in early school-age children, closer to the result of our study. Still, our results indicate poorer 
Table 4 The evolution of headache in subjects whose headache type has changed throughout the study

\begin{tabular}{llllll}
\hline $\begin{array}{l}\text { Case } \\
\begin{array}{l}\text { Reference } \\
\text { study }\end{array}\end{array}$ & $\begin{array}{l}\text { First } \\
\text { year }\end{array}$ & $\begin{array}{l}\text { Second } \\
\text { year }\end{array}$ & $\begin{array}{l}\text { Third } \\
\text { year }\end{array}$ & $\begin{array}{l}\text { Fourth } \\
\text { year }\end{array}$ \\
\hline 1 & TTH & M & M & M & M \\
2 & TTH & TTH & M & TTH & TTH \\
3 & TTH & TTH & M & PMG & TTH \\
4 & TTH & TTH & M & PMG & M \\
5 & TTH & TTH & M & PMG & M \\
6 & TTH & TTH & M & PMG & M \\
7 & TTH & TTH & M & PMG & M \\
8 & TTH & TTH & PMG & PMG & TTH \\
9 & TTH & TTH & PMG & PMG & TTH \\
10 & TTH & TTH & PMG & PMG & TTH \\
11 & Other & Other & TTH & TTH & TTH \\
12 & Other & Other & TTH & TTH & TTH \\
13 & Other & Other & TTH & TTH & TTH \\
14 & Other & Other & TTH & TTH & TTH \\
15 & M & M & M & PMG & Other \\
16 & M & M & M & PMG & Other \\
17 & M & M & M & TTH & TTH \\
18 & M & M & M & PMG & PMG \\
\hline
\end{tabular}

prognosis for adolescent headache than is suggested by any other published data.

Transformation of headache types is a frequent phenomenon. Eighteen subjects (20.69\%) had transformation of one type of headache type to another type during the study period. Some retained their original diagnoses at the last follow-up visit, and others did not. There is a group of adolescents whose headache type is highly unstable and transforms into other headache types in the spectrum. This is particularly significant in the 12- to 14-year-old group when compared with older adolescents $(p<0.01)$. This is a new finding and shows that adolescent headache might transform more than once throughout its course. Therefore, adolescent headache should be evaluated at every visit, and treatment should be tailored according to the ongoing situation. This observation of multiple transitions between headache types in a particular patient supports the headache continuum theory $[30,31]$.

Transformation from migraine to TTH was reported to be $8-32 \%$, and from TTH to migraine, $4-38 \%[17,18,21$, 23-29]. Transformation from migraine to another headache type was seen in four patients (8\%) in our study. Three of these four patients were in the 15- to 17-year-old group. Only one migraine headache transformed into TTH, and two into non-classifiable headache. Our results are different from those of other studies reporting transformation from migraine to TTH $[17,18,21,23-29]$. Only subjects suffering from a single headache type were included into this study; subject with the "mixed headache" of migraine and TTH were excluded. The migraine group included only migraineurs. Some studies, however, have included subjects with migrainous disorder and non-classifiable headache in the migraine group $[18,19,23,26]$. Another study considered only the most prevalent headache in the statistical analysis when patients had both migraine and TTH [21]. Using strict IHS criteria for migraine diagnosis, and forming a strict migraine group might have resulted in a transformation rate lower than those reported in other studies [17, 18, 21, 23-29]. It is obvious that transition of headaches from one type to another is more likely to be found in a mixed group.

Tension-type headache transformed into other headache types in 10 of 24 patients $(41.7 \%)$. Interestingly, all of these subjects' headaches transformed into migraine or probable migraine at least once during the follow-up period, and all of these subjects were in the younger age group. All but one of these subjects reported transformation two or three times. These subjects' headaches were the most unstable headaches. Our results are consistent with those previously reported in other studies [17, 21, 24-26, 28, 29]. Headaches in 69 subjects did not show transformation. However, even non-transforming migraineurs' headache, but not TTH sufferers' headache, showed some variability in symptoms.

Our study has some limitations. The number of subjects should be higher in such a study. Volunteers may represent subjects with the most severe headaches, and this might have caused selection bias. The rate of completion of the study $(62.59 \%)$ may seem low when compared with completion rates in studies using other methodologies (mail questionnaires, telephone interview, two evaluations with long follow-up periods). These rates varied between 70 and $90 \%$. One should consider the difficulty of compliance with a face-to-face annual follow-up study methodology in a highly mobile age group (moving to a high school or going to a university in a different city, starting paid work, or going to military service after high school). The sex and age difference between the study and dropout groups is another limitation of our study; however, analysis showed there was no difference between the sexes with regard to headache transformation. On the other hand, annual faceto-face interview is the strongest aspect of the study. This led to close observation of the evolution of headache by charting the annual course. Our findings show high variability of adolescent headache in a limited study sample from the general population of adolescents not seeking medical care. One should be aware of the probability of biased sample selection when interpreting the results of this study.

In conclusion, adolescent headache is a highly variable disorder. Headaches may transform into other headache 
Table 5 Course of headache characteristics, associated symptoms and trigger factors in 46 stable migraine sufferers (\%)

\begin{tabular}{|c|c|c|c|c|c|c|c|c|c|c|c|c|}
\hline \multirow[b]{2}{*}{$\begin{array}{l}\text { Attack frequency } \\
\text { (monthly) }\end{array}$} & \multicolumn{3}{|c|}{ Reference study (\%) } & \multicolumn{3}{|c|}{ First year $(\%)$} & \multicolumn{2}{|c|}{ Second year $(\%)$} & \multicolumn{2}{|l|}{ Third year $(\%)$} & \multicolumn{2}{|l|}{ Fourth year $(\%)$} \\
\hline & $\begin{array}{l}1-5 \\
(80)\end{array}$ & $\begin{array}{l}6-9 \\
(16)\end{array}$ & $\begin{array}{c}10-14 \\
(4)\end{array}$ & $\begin{array}{l}1-5 \\
(76)\end{array}$ & $\begin{array}{l}6-9 \\
(21)\end{array}$ & $\begin{array}{l}10-14 \\
(3)\end{array}$ & $\begin{array}{cc}1-5 & 6-9 \\
(77) & (20)\end{array}$ & $\begin{array}{c}10-14 \\
(3)\end{array}$ & $\begin{array}{cc}1-5 & 6-9 \\
(80) & (15)\end{array}$ & $\begin{array}{c}10-14 \\
(5)\end{array}$ & $\begin{array}{cc}1-5 & 6-9 \\
(79) & (19)\end{array}$ & $\begin{array}{c}10-14 \\
(2)\end{array}$ \\
\hline Attack duration (h) & $\begin{array}{l}1-4 \\
(30)\end{array}$ & $\begin{array}{l}5-24 \\
(60)\end{array}$ & $\begin{array}{r}25-72 \\
(10)\end{array}$ & $\begin{array}{l}1-4 \\
(26)\end{array}$ & $\begin{array}{l}5-24 \\
(62)\end{array}$ & $\begin{array}{r}25-72 \\
(12)\end{array}$ & $\begin{array}{cc}1-4 & 5-24 \\
(32) & (58)\end{array}$ & $\begin{array}{r}25-72 \\
(10)\end{array}$ & $\begin{array}{cc}1-4 & 5-24 \\
(35) & (55)\end{array}$ & $\begin{array}{r}25-72 \\
(15)\end{array}$ & $\begin{array}{cc}1-4 & 5-24 \\
(28) & (49)\end{array}$ & $\begin{array}{r}25-72 \\
(13)\end{array}$ \\
\hline \multicolumn{13}{|l|}{ Localization } \\
\hline Unilateral & 30 & & & 26 & & & 31 & & 28 & & 27 & \\
\hline Bilateral & 70 & & & 74 & & & 69 & & 72 & & 73 & \\
\hline \multicolumn{13}{|l|}{ Headache character } \\
\hline Pulsating & 99 & & & 100 & & & 100 & & 100 & & 100 & \\
\hline Pressure-like & 1 & & & 0 & & & 0 & & 0 & & 0 & \\
\hline \multicolumn{13}{|l|}{ Severity } \\
\hline Medium & 80 & & & 78 & & & 81 & & 75 & & 74 & \\
\hline Severe & 20 & & & 22 & & & 19 & & 25 & & 26 & \\
\hline \multicolumn{13}{|c|}{ Aggravation by routine physical activity } \\
\hline Yes & 60 & & & 66 & & & 91 & & 88 & & 90 & \\
\hline No & 40 & & & 34 & & & $9\left(p<0.05^{*}\right)$ & & $12\left(p<0.05^{*}\right)$ & & $10\left(p<0.05^{*}\right)$ & \\
\hline \multicolumn{13}{|l|}{ Nausea } \\
\hline Yes & 70 & & & 77 & & & 81 & & 95 & & 79 & \\
\hline No & 30 & & & 23 & & & $19\left(p<0.05^{*}\right)$ & & $5\left(p<0.05^{*}\right)$ & & $21\left(p<0.05^{*}\right)$ & \\
\hline \multicolumn{13}{|l|}{ Photophobia } \\
\hline Yes & 66 & & & 71 & & & 90 & & 88 & & 87 & \\
\hline No & 34 & & & 29 & & & $10\left(p<0.05^{*}\right)$ & & $12\left(p<0.05^{*}\right)$ & & $13\left(p<0.05^{*}\right)$ & \\
\hline \multicolumn{13}{|l|}{ Phonophobia } \\
\hline Yes & 55 & & & 61 & & & 89 & & 88 & & 88 & \\
\hline No & 45 & & & 39 & & & $11\left(p<0.05^{*}\right)$ & & $12\left(p<0.05^{*}\right)$ & & $12\left(p<0.05^{*}\right)$ & \\
\hline \multicolumn{13}{|l|}{ Stress } \\
\hline Yes & 55 & & & 70 & & & 90 & & 95 & & 88 & \\
\hline No & 45 & & & $30(p$ & $\left.<0.05^{*}\right)$ & & $10\left(p<0.05^{*}\right)$ & & $5\left(p<0.05^{*}\right)$ & & $12\left(p<0.05^{*}\right)$ & \\
\hline \multicolumn{13}{|l|}{ Wind } \\
\hline Yes & 30 & & & 32 & & & 30 & & 35 & & 40 & \\
\hline No & 70 & & & 68 & & & 70 & & 65 & & 60 & \\
\hline \multicolumn{13}{|l|}{ Hunger } \\
\hline Yes & 40 & & & 50 & & & 45 & & 60 & & 55 & \\
\hline No & 60 & & & 50 & & & 55 & & $40\left(p<0.05^{*}\right)$ & & 45 & \\
\hline \multicolumn{13}{|l|}{ Sleeplessness } \\
\hline Yes & 60 & & & 62 & & & 88 & & 95 & & 90 & \\
\hline No & 40 & & & 38 & & & $12\left(p<0.05^{*}\right)$ & & $5\left(p<0.05^{*}\right)$ & & $10\left(p<0.05^{*}\right)$ & \\
\hline \multicolumn{13}{|l|}{ Long Sleep } \\
\hline Yes & 68 & & & 70 & & & 65 & & 60 & & 62 & \\
\hline No & 32 & & & 30 & & & 35 & & 40 & & 38 & \\
\hline \multicolumn{13}{|l|}{ Food } \\
\hline Yes & 55 & & & 50 & & & 52 & & 50 & & 48 & \\
\hline No & 45 & & & 50 & & & 48 & & 50 & & 52 & \\
\hline
\end{tabular}

* Compared to reference study values

types more than once, highlighting the need to evaluate the pattern of headaches in adolescents. The transition of headache types from one to another (more than once in particular adolescents), and variability of diagnoses and headache features throughout the years strongly support the continuum theory. On the other hand, there might be other 
explanations including that the brain, particularly a developing brain, has a pluri-potentiality for generating different symptoms and symptom complexes. What is experienced by an adolescent at any one time may be no more than a random phenomenon that defies classification.

Conflict of interest None.

\section{References}

1. Karlı N, Akış N, Zarifoğlu M, Akgöz S et al (2006) Headache prevalence in adolescents aged 12 to 17: a student based epidemiological study in Bursa. Headache 46(6):649-655

2. Rother AD, Winner P (2001) Headache in children and Adolescents. In: Silberstein S et al (eds) Wolff's Headache and other head pain. New York, Oxford University Press, pp 539-561

3. Özge A, Buğdaycı R, Şaşmaz Y et al (2003) The sensitivity and specificity of the case definition criteria in diagnosis of headache a school-based epidemiology study of 556 children in Mersin. Cephalalgia 23:138-145

4. Buğdaycı R, Özge A, Şaşmaz T et al (2005) Prevalence and factors affecting headache in Turkish schoolchildren. Pediatr Int 47:316-322

5. Laurall K, Larsson B, Eeg-Olofsson O (2004) Prevalence of headache in Swedish schoolchildren, with a focus on tension-type headache. Cephalalgia 24:380-388

6. Lewis DW (2004) Toward the definition of childhood migraine. Curr Opin Pediatr 16:628-636

7. Mortimer MJ, Kay J, Jaron A (1992) Epidemiology of headache and childhood migraine in an urban general practice using Ad Hoc, Vahlquist and IHS criteria. Dev Med Child Neurol 34:1095-1101

8. Lipton RB, Stewart WF, Diamond S, Diamond ML, Reed M (2001) Prevalence and burden of migraine in the United States: data from the American Migraine Study II. Headache 41:646-657

9. Karli N, Akgöz S, Zarifoğlu M, Akiş N, Erer S (2006) Clinical characteristics of tension-type headache, migraine in adolescents: a student-based study. Headache 46(3):399-412

10. International Headache Society (2003) Classification and diagnostic criteria for headache disorders, cranial neuralgias and facial pain. Cephalalgia 24:24-36

11. Silberstein SD (1992) The role of sex hormones in headache. Neurology 42:37-42

12. Marcus DA (2001) Estrogen and tension type headache. Curr Pain Headache Rep 5:449-453

13. Sillanpaa M (1983) Changes in the prevalence of migraine and other headaches during the first seven school years. Headache 23:15-19
14. Abu-Arefeh I, Russell G (1994) Prevalence of headache and migraine in school children. BMJ 309:765-769

15. Rhee H (2000) Prevalence and predictors of headaches in US adolescents. Headache 40:528-538

16. Nachit-Ouinekh F, Chrysostome V, Henry P, Nachit-Ouinekh F, Chrysostome V, Henry P et al (2005) Variability of reported headache symptoms and diagnosis of migraine at 12 months. Cephalalgia 25(2):117-123

17. Guidetti V, Galli F (1998) Evolution of headache in childhood and adolescence: an 8-year follow-up. Cephalalgia 18:449-454

18. Camarda R, Monastero R, Santangelo G, Raimondo D, Puma D, Pipia C et al (2002) Migraine headaches in adolescents: a fiveyear follow-up study. Headache 42:1000-1005

19. Wang SJ, Fuh JL, Juang KD, Lu SR, Hsu LC, Chen WT et al (2004) Evolution of migraine diagnoses in adolescents: a 3-year annual survey. Cephalalgia 25:333-338

20. Bille B (1997) A 40-year follow-up of school children with migraine. Cephalalgia 17:488-491

21. Mazzotta G, Carboni F, Guidetti V, Sarchielli P, Felappa M, Gallai V et al (1999) Outcome of juvenile headache in outpatients attending 23 Italian headache clinics. Headache 39:737-746

22. Zebenholzer K, Wober C, Kienbacher C, Wöber-Bingöl C (2000) Migrainous disorder and headache of the tension-type not fulfilling the criteria: a follow-up study in children and adolescents. Cephalalgia 20:611-616

23. Monastero R, Camarda C, Pipia C, Camarda R (2006) Prognosis of migraine headaches in adolescents: a 10-year follow-up study. Neurology 67:1353-1356

24. Virtanen R, Aromaa M, Rautava P, Metsahonkala L, Anttila P, Helenius H (2007) Changing headache from preschool age to puberty. A controlled study. Cephalalgia 27:294-303

25. Gassmann J, Morris L, Heinrich M, Kröner-Herwig B (2008) One-year course of pediatric headache in children and adolescents aged 8-15 years. Cephalalgia 28:1154-1162

26. Laurell K, Larsson B, Mattsson P, Eeg-Olofsson O (2006) A 3-year follow-up of headache diagnoses and symptoms in Swedish schoolchildren. Cephalalgia 26:809-815

27. Metsahonkala L, Sillanpaa M, Tuominen J (1997) Outcome of early school-age migraine. Cephalalgia 17:662-665

28. Kienbacher C, Wöber C, Zesch HE, Hafferl-Gattermayer A, Posch M, Karwautz A et al (2006) Clinical features, classification and prognosis of migraine and tension-type headache in children and adolescents: a long-term follow-up study. Cephalalgia 26:820-830

29. Dooley J, Bagnell A (1995) The prognosis and treatment of headaches in children-a ten-year follow-up. Can J Neurol Sci 22:47-49

30. Silberstein SD (1992) Advances in understanding the pathophysiology of headache. Neurology 42:6-10

31. Cady RK (2007) The convergence hypothesis. Headache 47(Suppl 1):S44-S51 